\title{
O PIBID E A CONFIGURAÇÃO DA IDENTIDADE PROFISSIONAL: UMA ANÁLISE DA FORMAÇÃO DE PROFESSORES
}

\author{
PIBID AND THE CONFIGURATION OF PROFESSIONAL \\ IDENTITY: AN ANALYSIS OF TEACHER TRAINING \\ El PIBID Y LA CONFIGURACIÓN DE LA IDENTIDAD \\ PROFESIONAL: UN ANÁLISIS DE LA FORMACIÓN \\ DE PROFESORES
}

\begin{abstract}
Caroline Mariae Pereira ${ }^{1}$
TASSIANA Garcia LOPES ${ }^{2}$

Claudia Gomes ${ }^{3}$

${ }^{1}$ Universidade Federal de Alfenas (UNIFAL), Alfenas/MG- Brasil

${ }^{2}$ Universidade Federal de Alfenas (UNIFAL), Alfenas/MG- Brasil

${ }^{3}$ Universidade Federal de Alfenas (UNIFAL), Alfenas/MG- Brasil
\end{abstract}

\begin{abstract}
Resumo Este trabalho, com base nos pressupostos da Psicologia Histórico Cultural, discute a configuração da identidade profissional situada no contexto da formação inicial docente. Para tanto, o estudo lançou como objetivo analisar a contribuição das ações formativas desenvolvidas no âmbito do Programa Institucional de Bolsa de Iniciação à Docência PIBID, na configuração da identidade profissional de licenciandos de uma Universidade Federal da região Sul Mineira. O estudo, amparado na Epistemologia Qualitativa, contou com a participação de cinco acadêmicos do curso de Licenciatura em Química, que foram acompanhados ao longo das atividades desenvolvidas no âmbito do programa de formação PIBID. As informações construídas a partir da entrega de instrumentos de autopreenchimento aos acadêmicos e discussões grupais realizadas puderam ser categorizadas em dois núcleos de significação 1) Reconhecimento e Representação da Carreira Docente e 2) Configurações da identidade docente: condição para a autonomia profissional. Diante das análises, percebeu-se que o programa atua de forma potencializadora na consolidação da formação da identidade profissional e no desenvolvimento de ações reflexivas, ao favorecer processos de ressignificação acerca dos desafios e perspectivas da profissão nos dias atuais. Palavras-chave: Identidade Profissional; Formação de Professores; PIBID.
\end{abstract}


Abstract This work, based on the assumptions of Cultural Historical Psychology, discusses the configuration of the professional identity located in the context of initial teacher training. The purpose of this study was to analyze the contribution of the training actions developed within the scope of the Institutional Program of the Initiation to Teaching Grant - PIBID, in the configuration of the professional identity of graduates of a Federal University of the South Mineira region. The study, supported by the Qualitative Epistemology, was attended by five undergraduates from the Chemical Licensing course, who were monitored throughout the activities carried out under the PIBID training program. The information built from the delivery of self-completion tools to the academic and group discussions held could be categorized into two groups of meaning 1) Recognition and Representation of the Teaching Career and 2) Teacher identity configurations: condition for professional autonomy. In the face of the analysis, it was noticed that the program acts in a potentializing way in the consolidation of the formation of the professional identity and in the development of reflexive actions, favoring processes of resignification about the challenges and perspectives of the profession in the current days.

Keywords: Professional identity; Teacher training; PIBID.

Resumen Este trabajo, con base en los presupuestos de la Psicología Histórico Cultural, discute la configuración de la identidad profesional situada en el contexto de la formación inicial docente. Para ello, el estudio lanzó como objetivo analizar la contribución de las acciones formativas desarrolladas en el marco del Programa Institucional de Beca de Iniciación a la Docencia - PIBID, en la configuración de la identidad profesional de licenciandos de una Universidad Federal de la región Sur Minera. El estúdio, amparado en la Epistemología Cualitativa, contó con la participación de cinco académicos del curso de Licenciatura en Química, que fueron acompañados a lo largo de las actividades desarrolladas en el marco del programa de formación PIBID. Las informaciones construidas a partir de la entrega de instrumentos de auto-llenado a los académicos y discusiones grupales realizadas pudieron ser categorizadas en dos núcleos de significación 1) Reconocimiento y Representación de la Carrera Docente y 2) Ajustes de la identidad docente: condición para la autonomía profesional. Ante los análisis, se percibió que el programa actúa de forma potencializadora en la consolidación de la formación de la identidad profesional y en el desarrollo de acciones reflexivas, al favorecer procesos de resignificación acerca de los desafíos y perspectivas de la profesión en los días actuales.

Palabras Clave: Identidad Profesional; Formación de Profesores; PIBID.

\section{INTRODUÇÃo}

Ao observar o cenário contemporâneo de docência, discute-se muito sobre a importância da configuração da identidade profissional exercida ao longo do processo de formação inicial e continuada de professores. Atualmente, tem se observado que muito se estuda a respeito do assunto, na expectativa de criar cada vez mais espaços qualificados de formação que possibilitem aos acadêmicos não apenas um espaço de desenvolvimento téc- 
nico-científico em relação à profissão, mas sim uma formação humana, social e profissional que lhes possibilite vivenciar situações potencializadoras de sentidos para a configuração da identidade profissional.

Para Gatti e Barreto, em um estudo publicado pela UNESCO em 2011, a importância que o professor tem na sociedade e para a educação de pessoas cidadãs se torna cada vez mais reconhecida. Nesse sentido, a qualidade da formação inicial e continuada desse profissional vem sendo repensada pelas políticas de formação que geram impacto nas ações formativas ofertadas pelas universidades, as quais buscam, em projetos e programas, avançar de diferentes formas nos modelos curriculares.

De acordo com Gatti (2009), os métodos educativos institucionais têm uma grande influência na formação dos professores, porém, mesmo com os avanços ocorridos nos últimos tempos, tais práticas educativas formativas nem sempre parecem estar sendo potencializadoras da configuração da identidade profissional - aquisição de conhecimentos e valores, pois muitos dos recortes formativos ainda prezam o debate técnico como supremacia no que diz respeito aos aspectos relacionais, sociais e humanos da profissão docente.

Nesse sentido, as políticas de formação docente são enfáticas quanto à criação e manutenção de um espaço diferenciado para a formação de professores no âmbito da universidade. Exemplo claro é o Programa Institucional de Bolsas de Iniciação à Docência (PIBID), caracterizado como uma ação conjunta do Ministério da Educação, por intermédio da Secretaria de Ensino Superior (SESU) e da Fundação Coordenação de Aperfeiçoamento de Pessoal de Nível Superior (CAPES), que tem como finalidade fomentar a iniciação à docência e melhor qualificá-la, visando a melhoria do desempenho da educação básica (BRASIL, 2010).

O PIBID procura levar o futuro professor a atuar mais próximo à sociedade em que vai se inserir; sob o viés de que, dessa forma, as dificuldades poderão ser enfrentadas junto do auxílio de um supervisor e um coordenador e as habilidades desenvolvidas pelos licenciandos serão aperfeiçoadas gradualmente - de modo paralelo com as experiências vivenciadas no espaço formativo do programa. A metodologia do programa - que promove atuação dos licenciandos em escolas da rede pública de ensino e permite que esses se envolvam em atividades como elaboração de materiais didáticos, planejamento de atividades, participação de reuniões escolares e do dia a dia dos professores e educadores - proporciona o avanço das ações formativas ao objetivar a aproximação das instâncias formativas e favorecimento na configuração dos indicadores da identidade profissional (GOMES; FELÍCIO; BATISTA, 2016).

Nóvoa (1992) destaca que os programas e currículos para a formação de professores das universidades devem ser repensados, pois estes ainda indicam uma desvalorização da dimensão que as práticas pedagógicas representam, tomando, por vezes, o ensino como uma atividade que se concretiza naturalmente sem a intervenção de outrem. A experiência docente é um espaço de produção de conhecimento, exigindo que o professor desenvolva uma postura crítica sobre sua prática profissional. Esta análise implica em refletir criticamente sobre o que ensinar, como ensinar e para que ensinar. Sob essa perspectiva, deve ser considerada também uma reflexão acerca da postura docente nas relações com os alunos, bem como, nas inter-relações no sistema social, político, econômico e cultural. 
Ao lidar com a formação de professores, deve-se levar em conta as profundas transformações que ocorrem continuamente ao seu redor. Estas, pautadas na necessidade de inserção no mundo globalizado, tornam essencial uma constante integração do professorado às novas exigências de qualificação. Nesse cenário, encontram-se professores desmotivados e fragilizados pelo desprestígio da profissão (MAZOTTI, 2007; GATTI, 2009; GATTI; BARRETO, 2011).

Compreendemos que discutir os desafios e dilemas do contexto de formação e atuação docentes, nos dias atuais, demanda a necessidade de reconhecermos e nos apropriarmos de repertórios conceituais complexos e recursivos, que não visualizem uma leitura estática e linear do processo formativo, como podemos evidenciar a partir da proliferação das leis, propostas curriculares, programas de formação, entre outros, mas sim a partir da busca incessante de uma análise que "consiste precisamente em descobrir a conexão significativa entre as partes e o todo, em saber considerar o processo psíquico em conexão orgânica nos limites de um processo integral mais complexo" (VIGOSTKI, 1996, p. 149), referencial esse intitulado Psicologia Histórico Cultural, a partir de seu principal representante Lev Semyonovich Vigostki.

Com base nos postulados de Vigostki, o processo de mediação, neste estudo, definido como núcleo mediador da formação inicial de professores, deve favorecer a apropriação dos signos que, ao serem interiorizados, por meio de um processo recursivo, entre o sujeito e o contexto cultural que vivencia, resultam no desenvolvimento das funções psíquicas superiores do indivíduo (GOMES; BAZON; SOUZA, 2018).

Ainda de acordo com as autoras, com base nos estudos da Psicologia Histórico Cultural e da Pedagogia Histórico Crítica, devemos compreender a relevância do estudo dos processos de mediação na formação inicial de professores, não somente com o pressuposto de reflexão e crítica, mas também na relação "ação-problema-reflexão-ação", como uma sequência dialética que "desenrola o fio da existência humana" (SAVIANI, 1975, p. 10).

\begin{abstract}
Assim, não basta apenas o movimento de reflexão do sujeito, mas sim, uma real materialização em suas ações, de modo que construa e desenvolva funções psíquicas. É necessária a quebra da dicotomia existente entre reflexão e ação, de modo que exista a compreensão de que ambos são extremamente relevantes na formação e atuação profissional. É necessário que os profissionais se impliquem, em sua formação, com as próprias condições de aprendizado para que produzam sua existência (GOMES; BAZON, SOUZA, 2018, p. 8).
\end{abstract}

Para tanto, defendemos que o contexto de trabalho do profissional pode ser denominado um ambiente formativo, pois as habilidades necessárias que não são ensinadas nas instituições de ensino e as características construídas por profissionais só poderão ser desenvolvidas em um ambiente como esse (SILVA JR., 2010).

Ao individualizar a função ativa da formação inicial dos docentes para a atuação no seu trabalho, deve-se pensar na influência da mesma na constituição da profissionalidade e da sua profissionalização.

Profissionalidade é vista como o conjunto de características de uma profissão que enfeixam a racionalização dos conhecimentos e das habilidades necessários 
ao exercício profissional. E profissionalização como a obtenção de um espaço autônomo, próprio à sua profissionalidade, com valor claramente atribuído pela sociedade como um todo (GATTI; BARRETO, 2011, p. 93).

Em suma, deve-se buscar a valorização da profissionalidade dos docentes evidenciando sua importância e, dessa forma, buscar melhorias de sua formação e a consolidação de espaços que potencializem configurações implícitas, singulares e relacionais da profissão (MARCELO, 2009).

De acordo com Santos et al. (2008), o sujeito toma, a partir de motivos sociais, uma tendência para as suas ações, bem como, sua motivação no que se refere ao modo de se comportar. Ambos os fatores são ativados em um contexto social determinado, devido aos efeitos interpessoais sofridos por meio da influência social. Assim, percebe-se que é recorrente o uso de motivos para explicar as influências das ações sociais no sujeito e na construção de metas que ativam e direcionam sua ação. Não é possível separar, portanto, o $e u$ pessoal e o eu profissional numa carreira que envolver extrema relação humana. Essa indissociabilidade auxilia claramente a configuração de uma identidade profissional docente (ABRAHÃ̃, 2007).

Galindo (2004) define o processo de identificação: "Tomamos a identificação como um processo precursor da construção da identidade por surgir um vínculo ou atração, por parte do indivíduo, para algum objeto que esteja 'lá' onde ele deseja estar' (p. v 15). O sujeito, ao longo de sua vida, passa por várias transformações em decorrência de sua atuação na sociedade. Entre tais transformações, está a busca pela realização profissional. Direcionado pelo desejo do encontro da sua verdadeira identidade, o sujeito busca encontrar algo que faça um par entre sua idealização e a sua escolha profissional.

Assim, o convívio e a interação possibilitam a formação de uma identidade social. A identidade profissional, por sua vez, pode ser tratada da mesma maneira - um sujeito irá construí-la por meio da convivência e trocas de experiências. A ausência de tais oportunidades pode, ou não, trazer dificuldades em definir seu "eu mesmo" profissional (GALINDO, 2004).

Ainda, nesse sentido, avançarmos para a análise da configuração da identidade docente nos dias atuais exige repensarmos os espaços formativos, seja no âmbito inicial ou continuado, que possibilitem a constituição dos docentes como sujeito de suas ações. Espaços estes que favoreçam embates construtivos, que validem a reconfiguração de sentidos por meio de novas esferas de compreensão e de vivência, para que possam produzir suas ações e não apenas permanecerem à margem de posicionamentos ideológicos, políticos e profissionais, como reféns de seus próprios discursos e práticas (GOMES; SOUZA, 2010; 2011).

Em se tratando de identidade profissional, se manterá o foco da identidade docente; sobre essa, subtende-se que exige a aplicação da identidade social do profissional no meio em que se vive. Por intermédio dessa socialização vai se construindo e experimentando, pouco a pouco, as características emocionais, as relações simbólicas e as vivências profissionais com o outro e, assim, o sujeito pode viver e se ver como professor, buscando sua realização na carreira (MARCELO, 2009).

Entendemos, para tanto, que a identidade profissional do docente é uma elaboração que transcorre a vida acadêmica em diferentes fases, começando com a opção pela profissão, depois pela formação inicial e, por fim, a carreira profissional que se constrói nas 
experiências, nas escolhas, nas práticas e nos seguimentos, tanto no que diz respeito às representações, como no trabalho real (DEROUET, 1988).

A construção da identidade docente não se apoia apenas sob os conhecimentos científicos e técnicos adquiridos, mas também ao longo do trabalho em sala de aula, considerando a história de vida que carrega uma experiência social, cultural, religiosa, econômica, familiar, o início da carreira e os desafios enfrentados em sala de aula (OLIARI et al., 2012).

Junges (2006), em seu trabalho, enfatiza que o desenvolvimento, a construção e a percepção da ação do professor passam de reprodutora à crítica, pois ainda de acordo com o autor, a profissão exige técnica, bem como, consciência e criatividade. Quando o profissional é confrontado por essas características exigidas pela profissão, entende-se que a sua identidade docente vai sendo construída nesse meio.

Tornar-se um professor sujeito de sua história, que promova o desenvolvimento dos alunos e o seu próprio, é inserir-se em um processo recursivo e complexo e romper representações sociais e individuais que sustentam sua concepção de ensinar, de aprender, de desenvolvimento humano, de práticas de ensino-aprendizagem, ou seja, as ações consoantes às representações dos professores sobre regras, costumes e valores da instituição podem significar um posicionamento singular e histórico, que os firmam como sujeito de suas escolhas como docente, ainda que um sujeito submetido às condições materiais em que atua (GOMES; SOUZA, 2011; 2009).

A busca de novos modelos educacionais ressalta a importância de se ter um currículo diversificado que possa proporcionar ao professor e aos alunos uma educação de qualidade (GATTI, 2009). Para tanto, entendemos que a potencialização da construção da identidade docente só poderá ser efetivada quando avançar-se, também, na criação de um espaço formativo que propicie e envolva seus alunos-docentes em confrontações ideológicas, políticas, sociais e, acima de tudo, humanas, contribuindo para uma formação, e posterior atuação, que favoreça questionamentos e criticidade de seus próprios posicionamentos profissionais. Somente nesse contexto seria possível superar elementos técnicos reprodutivos e descontextualizados que tendem a perpetuar uma vida profissional submissa a condicionantes institucionais, que impediriam o desenvolvimento de novas experiências e, por conseguinte, a configuração de novos sentidos sobre a docência (GOMES; DUGNANI; RAMOS, 2018).

Assim, discutir a temática da formação de professores nos remete à necessidade de problematizar as deficiências e equívocos dos recortes curriculares formativos, não apenas no nível técnico e metodológico, mas prioritariamente, chamando a atenção para a inexistência de espaços e possibilidades de os licenciandos refletirem criticamente sobre as concepções e os conhecimentos acessados na formação. Tal condição faz que os alunos/profissionais fiquem impossibilitados de desenvolver perspectivas críticas de análise e compreensão das questões políticas, econômicas, sociais e ideológicas presentes na educação (GOMES, et al., 2014; GOMES; FELICIO; ALLAIN, 2014).

Para tanto, em nosso entendimento o Programa Institucional de Bolsas de Iniciação à Docência (PIBID), ao fomentar o aperfeiçoamento e valorização da formação de professores para a educação básica, nas Instituições de Ensino Superior em parcerias com as escolas da rede pública (CAPES, 2018), favorece sobremaneira a constituição de um campo formativo complexo, ao inserir e contemplar a formação do lócus da futura atuação profissional. 
Para Santos, Damasceno e Santos (2019), as ações formativas desenvolvidas pelo PIBID se constituem como importantes mecanismos para a formação da identidade docente, a partir das experiências diversificadas, instauradas por meio da relação dialógica diversificada entre os diferentes atores da instituição, que será solidificada na posterior atuação profissional.

Compreensão essa alinhada também às discussões lançadas por Obara; Broietti e Passos (2017), que constataram que a construção da identidade docente dos licenciandos é derivada das primeiras impressões a respeito da docência como profissão, manifestadas no lócus da formação acadêmica no âmbito do PIBID.

Para Lima, Silva e Caixeta (2018), as atividades desenvolvidas no PIBID, ao estreitarem as distâncias da formação acadêmica com o campo profissional, permitem aos licenciandos se apropriarem das demandas educacionais e escolares, a partir de uma experiência de inserção profissional e identificação com a docência.

Com base nessas considerações, esta pesquisa lançou como objetivo explorar a contribuição das ações formativas desenvolvidas no âmbito do Programa Institucional de Bolsa de Iniciação à Docência (PIBID) na configuração da identidade profissional dos estudantes de Licenciatura em Química de uma Universidade Sul Mineira.

\section{Procedimento metodológico}

Segundo Vigotski (1927/1995), o objeto e o método de investigação em psicologia mantêm uma relação muito estreita. Há que se ter claro, portanto, o objeto de estudo da psicologia, visto que ao se acercar dos fatos que se pretende investigar (o objeto de pesquisa), o pesquisador já o faz de certa perspectiva metodológica: "A elaboração do problema e do método se desenvolvem conjuntamente, ainda que não de modo paralelo. A busca do método se converte em uma das tarefas de maior importância na investigação" (1995, p. 47). Para o autor, o objeto de investigação da psicologia, segundo Vigotski, é o sujeito histórico e o materialismo histórico e dialético o fundamento epistemológico que garante a adequação do método ao objeto de estudo.

Dentro dessa compreensão da produção do conhecimento, que não pode ser operacionalizada pelas vias tradicionais de pesquisa, a Epistemologia Qualitativa aparece como uma possibilidade de sistematizar princípios de uma vertente de pesquisa de abordagem qualitativa, capaz de integrar aspectos dialéticos e complexos das realidades estudadas.

A Epistemologia Qualitativa, formulada por Gonzalez Rey (2002) tem como foco a busca pela "produção de conhecimento em psicologia que permita a criação teórica acerca da realidade plurideterminada, diferenciada, irregular, interativa e histórica, que representa a subjetividade humana" (p. 38), e para tanto, apresenta três princípios fundamentais a serem considerados: a produção construtiva interpretativa; a significação da singularidade na produção de conhecimento; e por fim, o caráter interativo do processo de produção científica (GONZALEZ REY, 2002).

Para tanto, participaram da pesquisa cinco acadêmicos do curso de Licenciatura em Química - vinculados ao Programa Institucional de Bolsas de Iniciação à Docência (PIBID), de uma Universidade pública da região Sul Mineira.

Em relação às variáveis sociodemográficas, a idade média dos entrevistados é de 21 anos, sendo dois participantes homens e três mulheres, todos com mais de dois anos de 
participação no programa. Já em relação à caracterização da escolha profissional, pudemos evidenciar que dos cinco participantes apenas dois participantes afirmam ter a escolha profissional pela docência ao ingressarem no curso, outros dois participantes iniciaram o curso de Licenciatura com dúvidas e na perspectiva de uma formação em bacharel ao invés da docência, assim como um dos participantes, que iniciou o curso sem identificação alguma com a área. Entendemos que a diversidade na caracterização da escolha profissional dos participantes favorece uma análise importante do programa, frente às diferentes aspirações e demandas profissionais.

Vale ressaltar que a pesquisa contou com a aprovação do Comitê de Ética em pesquisa com seres humanos, Parecer n. 1.126.033, garantindo todos os preceitos éticos e resguardo à identidade dos participantes. Para tanto, a descrição das falas e as expressões literais dos participantes serão indicadas a partir da categorização. Assim, os relatos que estruturam os respectivos núcleos de análise são apresentados a partir da categorização Licenciandos/ PIBID, e o código (A; B; C; D; E) para a identificação de cada um dos participantes.

Como recursos de coleta de informações, foram utilizados instrumento de autopreenchimento com seis questões abertas diretivas objetivando caracterizar os motivos da escolha profissional, expectativas em relação à docência, avaliação de características da docência e do professor como profissional, perspectivas quanto à docência antes e depois da vivência no PIBID.

E ainda um roteiro de posicionamentos e análises de situações cotidianas da educação direcionadas por fragmentos de reportagens e pesquisas atuais, essas reportagens foram retiradas de revistas educacionais (por exemplo, Nova Escola, Revista Nacional de Educação, entre outras) de circulação nacional, e foram abordadas questões como: evasão docente, formação inicial de professores e desvalorização profissional.

Esses roteiros foram entregues individualmente para que fossem respondidos, seguidos de orientações relacionadas ao tempo de preenchimento que os licenciandos teriam para responder às questões diretivas, podendo se expressar da forma como quisessem e sem nenhuma forma de pressão ou obrigação por serem participantes do Programa de Bolsa de Iniciação à Docência.

Após a transcrição das informações, como procedimentos de análise dos dados, optou-se por uma categorização com base nas questões indicadas nos instrumentos - que possibilitaram uma leitura de reconhecimento das informações e, posteriormente, estabelecimento dos eixos de análise (AGUIAR; OZELLA, 2013). Ancorados na identificação prévia de palavras e contextos constantes nos relatos dos participantes, foi feita a seguinte distinção entre eles: 1) Reconhecimento e Representação da Carreira Docente e 2) Configurações da identidade docente: condição para a autonomia profissional.

\section{RESULTADOS E DISCUSSÕES}

Com base nos relatos dos participantes da pesquisa e no objetivo de discutir a perspectiva de formação da identidade docente a partir da vivência em um curso de graduação, bem como, em programas que viabilizam tal processo, pode-se evidenciar que as discussões e perspectivas dos entrevistados em relação à docência são amparados por indicadores 
distintos. Dessa forma, viu-se a necessidade de dividir os relatos em dois eixos principais: 1) Reconhecimento e representação da carreira docente e 2) Configurando a Identidade docente: condição para a autonomia profissional.

\section{Categoria 1: Reconhecimento e representação da carreira docente}

Em relação à categoria Reconhecimento e representação da carreira docente, pode-se evidenciar discussões pertinentes quanto aos indicadores de análise da profissão e atuação, que enfocam elementos como evasão docente, desistência da carreira profissional, desafios da formação que englobam o currículo da graduação, formação inicial e valorização profissional.

O primeiro indicador de análise que potencializa discussões importantes quanto às condições de trabalho docente, e apontado como consenso dos participantes, é a consideração de que um dos principais motivos para a evasão docente é a desvalorização profissional, como pode ser observado nos diálogos a seguir.

"O profissional que forma os demais profissionais é o professor... Dessa forma, é necessário que haja uma valorização mais consolidada nas condições de trabalho dos docentes. Atualmente, os baixos salários, as escolas em ruínas e alunos que não possuem interesse fazem com que todo o trabalho de um professor seja inútil e justifica a escolha de se trabalhar nas outras áreas, onde a vida pode ser vivida dignamente, com remunerações que deem conta das verdadeiras necessidades do profissional, além ter acesso a aparatos e dispositivos que possibilitem o trabalho, de forma mais técnica, do professor [...]" (LICENCIANDO A/PIBID).

O relato mencionado se refere à desvalorização profissional docente por meio das esferas sociais e econômicas, questão essa entendida pelos participantes como um dos principais fatores para a evasão profissional. De acordo com Nóvoa (1992), o professor vive um conflito ao longo de sua carreira, pois não tem total autonomia dentro de sala de aula, visto que tem que cumprir normas impostas pelos regulamentos, que, entretanto, não demonstram um reconhecimento da importância desse profissional na sociedade, como novamente é evidenciado por outro entrevistado em:

“[...] desvalorização da profissão docente não se iniciou de uma hora pra outra, vários fatores foram interferindo, assim como para a valorização vários fatores devem ser considerados e melhorados... Não se pode esperar que por alunos de classes $\mathrm{C}, \mathrm{D}$ ou $\mathrm{E}$ estarem ingressando nas licenciaturas vá diminuir a qualidade do ensino [...]" (LICENCIANDO B/PIBID).

Pode se observar nos relatos que os licenciandos acabam incorporando e se tornando agentes de sua própria desvalorização, principalmente porque alguns participantes cursando a licenciatura não indicam certeza e segurança em sua escolha profissional, fato que pode favorecer apenas a compreensão da docência como um trabalho "alternativo" sem vínculo com a profissão e que, portanto, não será provedor da mudança da realidade atual. 
A formação se consolida por intermédio da atividade reflexiva exercida pelo profissional sobre as práticas de construção permanente de uma identidade pessoal. Segundo Rankel (2009), a identidade docente é caracterizada por meio da identidade construída, externamente, pelo Estado e pela sociedade em contato com o professor e, internamente, uma identidade pessoal construída pelo indivíduo. Ainda, de acordo com esse autor, há uma grande demanda de professores para a educação, muito embora essa profissão esteja desvalorizada, fazendo que o professorado seja formado por pessoas que não se identificam com a profissão ou, até mesmo, por uma classe de pessoas diferente da precursora.

O processo dessa desconstrução da identidade docente pode ser reflexo do pouco reconhecimento que os profissionais têm, das parcas condições de trabalho, da responsabilidade acerca do processo de ensino e aprendizagem e do desempenho deles exigido pela sociedade, que, juntamente ao Estado, é omissa e deixa de reconhecer sua importância. Em decorrência disso, é comum que professores comecem a apresentar problemas de saúde provenientes das frustrações na profissão que escolheram.

Nesse sentido, não podemos desconsiderar que o chamado social ao docente, por uma educação que cada vez menos tem a definição de suas atribuições como instituição promotora do desenvolvimento histórico, social e científico, e frente a uma formação fragmentada como evidenciado nas discussões anteriores, a perspectiva prática com a aquisição de Kit de sobrevivência profissional, como definido por Libâneo (2012) é uma das perspectivas mais demandadas para a formação e atuação. E, para tanto, a configuração de um contexto formativo que possibilite a formação para a docência da realidade educacional e escolar, ações essas objetivadas pelo PIBID, se mostram efetivas para o processo de constituição da identidade profissional docente (OBARA; BROIETTI; PASSOS, 2017).

Se os profissionais não dedicam um tempo somente para a reflexão de suas práticas, estas seguirão sempre um modelo pedagógico que pouco influencia mudanças na forma como os professores veem o futuro da profissão. Essa realidade é muito bem ilustrada na seguinte fala de um dos participantes:

“[...] O fato de a licenciatura estar desvalorizada envolve vários aspectos socioculturais. Portanto, para mudar o quadro, vários fatores precisam mudar... professor se valorizar e assumir a carreira que escolheu motivando a outras pessoas, melhorias salariais não sobrecarregariam tantos os professores que precisa dobrar turno deixando os planejamentos em segundo plano [...]" (LICENCIANDA E/PIBID).

Mesmo que os entrevistados ainda não tenham assumido a profissão, suas respostas apontam que o contato tido com profissionais atuantes ajudou a criar uma imagem de desvalorização da profissão e, por isso, muitos se sentem desmotivados quanto à ideia de lecionar um dia. Lembrando que os relatos mencionados provêm de licenciandos que participaram do PIBID, pode-se perceber que eles apontam vários fatores que, a seu ver, contribuem para a desvalorização profissional e também nos provocam o seguinte questionamento: $a$ vivência no programa possibilita outra compreensão da profissão ou vem se tornando um "eco" das realidades institucionais, sem perspectivas de transformação? 
Desafio esse de rearticular a dicotomia já indicada há tempos com a consideração de que parte da desqualificação do trabalho docente nos dias atuais pode ser resultado do modelo de formação das licenciaturas curtas, predominantemente estruturadas com base na dicotomia: preparação pedagógica/conhecimento específico; preparação para o ensino/ preparação para a pesquisa; preparação teórica/preparação prática (FONSECA, 1997), e que se mantêm ainda com a avaliação dos estudos quanto aos currículos formativos, evidenciando uma ausência clara de um perfil profissional; isso sem falar nas temáticas desvinculadas da prática profissional (GATTI; BARRETO, 2009).

Concordamos com Gatti (2010), quando afirma que, atualmente, os cursos de licenciatura precisam ser estruturados de modo a promover a profissionalização do professor, constituído por uma "base sólida de conhecimentos e formas de ação, [...] capacitado para construir soluções em sua ação, mobilizando seus recursos cognitivos e afetivos" (2010, p. 1.360).

Outro indicador de análise em relação ao reconhecimento e representação da carreira docente é o debate da qualidade da formação. De modo geral, os participantes atrelam a qualidade da formação à compreensão social da profissão, como evidenciado no seguinte relato:

“[...] Como já explicitado anteriormente, o problema na formação docente está nos buracos que a sociedade possui em termos de formação humana... Além disso, ser professor, há algum tempo atrás, era sinônimo de status e título, o que faz com que as famílias mais simples e que não ambicionam um futuro mais grandioso depositem seus filhos nos cursos [...]" (LICENCIANDA D/PIBID).

No relato citado, o licenciando disserta sobre a valorização do curso perante a sociedade. Ele destaca os problemas relacionados aos novos alunos que ingressam no curso, geralmente de classes menos favorecidas economicamente e que, por terem um acesso facilitado, acabam se tornando o estereótipo dos cursos de licenciatura. Nesse sentido, esses cursos acabam se tornando um concentrado de pessoas que possuem um histórico de formação deficiente, como é explicitado no próximo relato.

“[...] Eu até entendo essa postura de queda pela procura na licenciatura tendo como foco esses argumentos, já que o professor é o profissional que instrui todos os outros profissionais desde a alfabetização até a formação profissional. Realmente o quadro é triste e acredito que a mudança é possível, porém árdua. O que não pode acontecer é se desmotivar" (LICENCIANDA E/PIBID).

Porém, muitos depositam a responsabilidade de garantir uma formação de qualidade à instituição de ensino que forma o futuro professor, como no relato a seguir: "[...] cabe a instituição garantir que seus profissionais sejam tão competentes quanto os que eram formados anteriormente [...]" (LICENCIANDA C/PIBID).

Evidencia-se, nesse trecho, a seguinte visão do licenciando frente à formação profissional: que a responsabilidade é inteiramente da instituição formadora. No entanto, responsabilizarmos as instituições formativas é antes provocarmos as discussões quanto à definição curricular ainda predominante nos cursos de licenciatura, que muitas vezes são desconectados da realidade social e econômica das escolas públicas brasileiras, com o predomínio dos conteúdos técnicos e metodológicos favorecendo uma formação acrítica e de pouco impacto para a transformação social. 
O mundo contemporâneo está em constante transformação e a globalização afeta continuamente o cenário de qualificação dos professores, por isso, quanto à formação docente, Mazotti (2007) ressalta a necessidade de se estar conectado às novas inserções da globalização. Dessa forma, as constantes mudanças sofridas pela sociedade geraram uma considerável demanda de novas profissões, das quais algumas são mais valorizadas e melhor remuneradas que a do professor. É perante tal cenário que se pode encontrar professores desmotivados e fragilizados pelo desprestígio da profissão.

Nesse sentido, a ânsia dos programas, entre os quais se destaca o PIBID, é de fornecer "novos" ambientes formativos, vinculados ao contexto de trabalho, e também parceria formativa, a qual conta com a participação da escola no desenvolvimento de habilidades necessárias para exercer a função. Acredita-se que essa experiência é favorável à construção do professor como profissional, visto que assim é possível conhecer os enfrentamentos pelos quais ele deverá passar, já que muitos deles só acontecem na realidade vivida do ambiente de trabalho (SILVA JR., 2010; SANTOS; DAMASCENO; SANTOS 2019).

Dessa forma, seja na discussão nos espaços universitários ou no interior dos programas de formação docente, o elemento curricular é o núcleo dos debates da qualificação da formação. O currículo, tanto para as escolas quanto para o professor deve ser melhorado, buscando inovações a fim de obter um modelo diversificado que atenda às necessidades educacionais com qualidade para proporcionar uma melhor formação. Considerando tal perspectiva, não se pode deixar de apontar que a problemática da formação é também anterior à entrada do aluno nos cursos de licenciatura. Problematizar essa questão é debater mudanças na formação básica, partindo da educação infantil e chegando ao ensino superior, e, assim, minimizar as dificuldades encontradas pelos graduandos quanto à deficiência proveniente da educação básica (GATTI, 2009).

Ainda, de acordo com a autora, é importante ter uma formação inicial sólida e reconhecida, colocando a formação do professor para além do improviso, com uma direção de superação de uma posição missionária. Assim, ele assumirá um papel de profissional que tem condição de confrontar os problemas advindos da docência, estando capacitado para construir soluções em sua ação, por meio de recursos cognitivos e afetivos.

Segundo Vigostki, o homem não é apenas um produto de seu ambiente, este também um agente ativo no processo de criação desse meio (2005, p. 25). Por intermédio da interação social o homem recebe do meio toda a experiência historicamente acumulada pela humanidade, ou seja, a inserção social e cultural possibilita ao indivíduo se constituir e influencia suas atitudes e pensamentos.

Nessa perspectiva, o que fica evidenciado, com base na categoria analisada, é que a compreensão da representação social da profissão, seus desdobramentos e desafios para a formação inicial e continuada de professores, é favorecida pelo PIBID num espaço que proporcione aos alunos avançarem em suas próprias análises, distanciando-se dos "ecos institucionais" e, dessa forma, reafirmarem a escolha profissional a partir da vivência no espaço escolar (OBARA; BROIETTI; PASSOS, 2017; LIMA; SILVA; CAIXETA, 2018). Tal colocação é claramente representada nos seguintes relatos: 
“[...] Eu não imaginava o quão complexo era o processo de formação e preparação à docência [...]" (LICENCIANDA E/ PIBID)

“[...] Eu não imaginava como seria o curso de licenciatura [...]” (LICENCIANDA C/ PIBID)

“[...] Antes de iniciar no curso de licenciatura não imaginava como o processo de formação e preparação era complexo [...]" (LICENCIANDO A/ PIBID)

"[...] contato com formas de ensinar e teorias educacionais [...]" (LICENCIANDO B/ PIBID)

"[...] sempre achei que teria uma "receita" para quando entrasse em sala de aula [...]" (LICENCIANDO D/ PIBID).

O questionamento sobre o PIBID proporcionar um espaço efetivo de configuração a respeito da docência para além das representações sociais é alarmado com base nos relatos de alguns licenciandos, os quais apontam em seus relatos que, ao ingressar na licenciatura, esperavam uma forma padrão para se ensinar, como se todo professor tivesse um modelo ou roteiro a seguir.

Nesse sentido, não podemos desconsiderar o chamado social ao docente por uma escola que cada vez menos tem a definição de suas atribuições como instituição promotora do desenvolvimento histórico, social e científico. Frente a uma formação fragmentada, como evidenciado nas discussões anteriores, a perspectiva prática com a aquisição de mecanismos práticos de sobrevivência profissional sofre com grandes falhas. Assim, faz-se necessário problematizar se tal demanda formativa e de atuação não vem potencializando os motivos formativos desses alunos e, assim, configurando os elementos de sentidos que demarcam a sua vivência no programa (GOMES; SOUZA, 2014).

De acordo com Junges (2006), a profissão docente exige, além de técnica (esta pode ser estudada e aperfeiçoada nas instituições de ensino), consciência e criatividade por parte do profissional; e que a percepção da ação do professor deve passar de reprodutora à crítica, o que só poderá ser desenvolvido no exercício da profissão.

No entanto, ao mesmo tempo em que consideram as relações cotidianas nas escolas como dimensões formativas importantes, os sentidos derivados desta convivência evidenciam a profissão docente como ação delimitada por domínio técnico e metodológico, que configuram em nosso entendimento o desafio central do PIBID. A definição de outra esfera formativa, muitas vezes indicada pelos alunos como contraposição ao espaço de formação teórica ofertado na universidade, nos indica que as ações do programa parecem compreendidas pelos licenciandos como um espaço real, porém independente, que potencializa a configuração de sentidos da docência como uma demanda de domínios técnicos, metodológicos e relacionais (GOMES; DUGNANI; RAMOS, 2018).

$\mathrm{O}$ apontamento de que na escola o licenciando tem conhecimentos e acesso à temáticas que, aparentemente, não são ofertadas pelos pressupostos teóricos da formação, e que são esses elementos os nucleares para uma formação docente de qualidade, nos inquieta a ponto de questionarmos se o programa não estaria apenas polarizando os elementos da formação, postulando, em um novo formato, a relação teórica e prática - com maior peso da prática, ao invés de constituir-se como polo de mediação e de configuração plena de identidade e profissionalização docente (GOMES; SOUZA, 2014). 


\section{Categoria 2: Configurando a identidade docente: condição para a auto- nomia profissional}

Os relatos analisados e enquadrados dentro desta categoria demonstram a concepção da carreira docente criada ao longo da formação inicial. Esses relatos evidenciam o surgimento de características que remetem à formação da identidade profissional. A princípio, deve-se analisar a forma mais adequada de se tratar identidade profissional.

Assim, se faz necessário entender o que é identidade e como esta se relaciona com a profissionalidade. Segundo Galindo (2004, p. 15), a identidade é "[...] um processo de construção de sujeito enquanto profissionais". Portanto, entende-se que as vivências do sujeito irão contribuir de forma direta na construção da sua profissionalidade. O que podemos evidenciar nessa categoria é que, para além da representação da profissão docente, o espaço formativo potencializa condições e configurações autônomas de enfrentamento e análise da realidade profissional, o que é bem ilustrado em:

"[...] antes de ingressar na carreira nós sabemos quantas horas trabalharemos
e quanto receberemos por tal. O que não impede que continuemos buscando
melhorias tanto para nós educadores quanto para os nossos alunos [...]" (LI-
CENCIANDO A/PIBID).

“[...] antes de ingressar no curso de licenciatura é de conhecimento de todos que a profissão é desvalorizada" (LICENCIANDO B/PIBID).

Nos relatos mencionados, os licenciandos demonstram conhecimento da realidade docente, porém, isso não os impede de querer atuar como professores. Bolívar (2006) afirma que as mudanças ocorridas nas últimas décadas com relação à docência dificultam a construção de uma identidade profissional, já que se percebe um quadro no qual o sistema escolar não faz tanto sentido quanto antes.

As mudanças, discutidas pelo autor, influenciam diretamente nos discursos dos professores quanto à valorização profissional. Ao entrar em contato com os professores durante a formação inicial, os licenciandos constroem suas visões e atribuem valores essenciais à carreira docente. Assim, os discursos desses profissionais influenciam também a perspectiva daqueles que ainda estão na graduação.

A construção da identidade profissional é dada de acordo com a relação que o docente estabelece com a sua profissão e com a comunidade escolar; a construção simbólica que essas relações implicam em um campo pessoal e interpessoal, levam em consideração as elaborações que os professores têm a respeito da atividade docente (TARDIF; LESSARD, 2005).

Pode-se evidenciar que os discursos apontam anseios pela mudança da realidade atual e que uma valorização melhor dessa profissão partirá dos próprios profissionais. A desvalorização da profissão e os desafios enfrentados durante a atuação, como condições de trabalho e salário, exigem do profissional um posicionamento mais centrado, o que não lhe é proporcionado durante a sua formação inicial.

“[...] é acreditar no ensino, que pode haver educação de qualidade desde que o professor se comprometa a isso e não meça esforços para que isso aconteça mesmo levando em consideração todas as dificuldades que serão encontradas no dia a dia dessa profissão [...]" (LICENCIANDA E/PIBID). 
Percebe-se no excerto mencionado que o aluno aponta que a transformação da realidade só ocorrerá a partir do momento em que os professores decidam enfrentar as dificuldades encontradas durante a carreira e que estas não devem ser motivos para desistirem de uma educação de qualidade ou razões para que haja falta de comprometimento por parte do profissional. Ao se consolidar a identidade docente durante a formação, o impacto de tais dificuldades poderá ser minimizado na postura desse profissional.

Nóvoa (2012) afirma que é essencial incorporar na cultura pedagógica teorias e perspectivas que se desenvolveram nos últimos anos dentro do campo científico, e que ainda não foram integrados no espaço da educação e das nossas reflexões sobre a educação. É fundamental para a formação dos professores incorporar espaços que potencializam a reflexão das práticas, concebendo que o ensino não se estabelece como uma atividade de transmissão de um conhecimento preexistente, mas que esse conhecimento pode ser utilizado como matéria-prima que elabore um conhecimento novo no próprio ato pedagógico.

Ainda, Santos; Antunes e Bernardi (2008) afirmam que é a partir de motivos sociais que o sujeito, no caso o professor, determina a inclinação de suas ações e que esta só será ativada quando o sujeito estiver inserido em um contexto social determinado. Portanto, os programas que possibilitam aos alunos do curso de graduação participar de ações dentro da escola (da rotina de um professor, dos planejamentos, dos recursos que possuem a disposição para serem utilizados), permitirão também que as ações tomadas por licenciandos sejam predefinidas.

De acordo com Hypolito et al. (2003), devem ser atualizados os debates conceituais sobre o trabalho docente, currículo e o efeito destes na constituição das identidades profissionais e sociais, valorizando as novas formas de intervenção política na educação. Alguns trabalhos como os desenvolvidos por Anadon (2003) e Venzke (2003) investigam o modo como as professoras e professores percebem as transformações que ocorrem no âmbito das escolas públicas pelas políticas educacionais neoliberais e o impacto na identidade profissional dos mesmos.

De acordo com Martins (2012), a função nuclear do desenvolvimento tem como cerne a mediação em superar os saberes espontâneos no deslocamento para os saberes sistematizados. Defender uma ação docente com a função de uma atividade mediadora incide que "[...] a rigor, se identifique com a atividade que, interpondo-se na relação sujeito-objeto, provoca transformação" (p. 222). Segundo a autora, para que o indivíduo conquiste a aquisição das máximas propriedades da realidade, não dispostas à compreensão imediata, requer que a função basilar da educação seja a transmissão dos conhecimentos objetivos, universais como processo mediado.

Sob o desejo de mudanças no ensino, muitos licenciandos anseiam por ideias e ideais que busquem alterar de forma benéfica a educação atual no Brasil. É considerado assim, de forma vigente, as dificuldades e a frequente desvalorização na profissão professor, o que, por vezes, acarreta num desestímulo ainda precoce dos alunos na formação inicial chegam à escola com sede de mudanças e se deparam com uma realidade contrária ao que esperavam. Mesmo depois de vivenciar a experiência que o PIBID proporciona, o discurso não se altera muito, como pode ser reconhecido em "Modificação de práticas existentes, cooperação entre profissionais, desvalorização por parte do governo e condições mínimas de trabalho" (LICENCIANDA C/PIBID). Assim, é notória a necessidade de melhorar a 
qualificação de quem está em sala e ainda estimular a formação de novos professores para atender às atuais e futuras demandas (OBARA; BROIETTI; PASSOS, 2017; LIMA; SILVA; CAIXETA, 2018).

Durante a formação inicial docente, aspectos como a desvalorização precoce podem influenciar no processo de construção do ser profissional. De acordo com Galindo (2004), a construção do ser acontece em suas interações sociais e em como este se define no desempenho de seu papel social. Por intermédio dessas relações interpessoais, o sujeito se define na sociedade, assim como incorpora as definições de como é reconhecido pelos outros.

Ainda como base na análise desta categoria, evidencia-se qual o impacto gerado pelo PIBID na formação inicial dos licenciandos. Quando os candidatos são questionados com relação ao motivo da escolha pela carreira docente, de modo geral as respostas não evidenciam um desejo anterior por essa profissão, antes mesmo de ingressar no curso.

\footnotetext{
"[...] Comecei o curso de licenciatura, mas na verdade meu interesse era outro curso [...]" (LICENCIANDA D/PIBID)

"Na verdade, não me passava pela cabeça ser professora [...]" (LICENCIANDA C/PIBID)

“[...] não havia escolhido claramente a docência [...]” (LICENCIANDO B/PIBID).
}

Muitas dessas escolhas foram movidas pela afinidade com o conteúdo químico que seria estudado durante o curso. A formação desses profissionais é influenciada tanto pelo estudo teórico quanto pelas transformações sociais no meio que este está inserido. Essas transformações exigem do profissional que possua uma formação polivalente, como afirma Gatti (2009), para que este esteja preparado para diferentes cobranças do mundo globalizado.

Segundo Martins (2012), a complexidade da ação mediadora é caracterizada como uma interposição que provoca transformações, para além das intencionalidades socialmente construídas e deve promover efetivo desenvolvimento. No entanto, o que evidenciamos é que alguns alunos não encontram na profissão docente sua identidade, o que pode justificar muitos pensamentos de não se querer, no início, a docência, mas permanecer no curso por falta de opção. De modo geral, ao serem questionados quanto à expectativa antes de iniciarem o curso de licenciatura, os participantes não demonstram conhecimento do processo de formação, alegando muitas vezes nos diálogos que é algo complexo.

\footnotetext{
"Eu não imaginava o quão complexo era o processo de formação e preparação à docência [...]" (LICENCIANDO A/PIBID)

"Eu não imaginava como seria o curso de licenciatura [...]" (LICENCIANDO B/PIBID)

"Antes de iniciar no curso de licenciatura não imaginava como o processo de formação e preparação era complexo [...]” (LICENCIANDA E/PIBID).
}

A partir dos relatos, percebe-se que os licenciandos vivenciam tensões ao longo do curso, o que não necessariamente está vinculado ao domínio dos conteúdos químicos, mas sim nos desencontros e provocações derivadas na/da ação docente relacional, por exemplo, as atividades em sala de aula, a elaboração de planos e adequação ao que é pedido, o contato com os alunos, as relações e dinâmicas sociais, entre outras. 
Gomes; Dugnani e Ramos (2018) trazem algumas discussões a respeito de currículo e a busca por uma formação que possa proporcionar aos futuros educadores um suporte mais completo para um ensino de qualidade. Porém, a formação de educadores vai além de se pensar um currículo de qualidade; é necessário que haja mais espaços formativos que proporcionam o desenvolvimento frente a confrontos sociais, políticos que favoreçam também o desenvolvimento crítico e exijam posicionamentos profissionais (OBARA; BROIETTI; PASSOS, 2017; LIMA; SILVA; CAIXETA, 2018; DAMASCENO; SANTOS 2019).

Assim, surgem questionamos se um novo limiar "real" de análise para a formação não exigiria uma formação acadêmica com novos rumos e direcionamentos. Torna-se evidente que um dos indicadores de sentido configurado pelos alunos na vivência no PIBID se refere "a oportunidade de reconhecimento e desvelamento da realidade escolar", fato esse atrelado à necessidade constante de uma postura reflexiva. Não podemos contribuir para a perpetuação da lógica de que a vivência acadêmica é desvinculada de uma realidade vivida, nem tampouco que a realidade é explicada por si só. Ambos os processos são fundantes da cisão entre teoria e prática na formação de professores (GOMES; SOUZA, 2014).

No entanto, também compreendemos que enquanto tais ações reflexivas não se materializarem na constituição e desenvolvimento psíquico dos licenciandos, continuaremos a observar na formação a reflexão e a ação como atividades distintas e de dimensões de importância diferenciadas - ora com peso maior na reflexão, ora com peso maior na ação, ainda comum e presente nos modelos de formação e atuação profissional (GOMES; SOUZA, 2014).

Com base nos relatos em relação às expectativas dos participantes do PIBID e, ao fim do curso, em relação à docência, evidenciamos que o programa vem criando possibilidades e análises positivas na compreensão da realidade e ação docente, como evidenciado nas seguintes falas dos participantes, ao apontarem os planos na carreira de trabalho:

\footnotetext{
"Prosseguir os estudos em termos de pós-graduação e pesquisa atuando[...]" (LICENCIANDO A/PIBID)

"Realmente é o que eu quero...sempre estudar novas práticas de ensino, novos recursos de modo a atender uma sala heterogênea" (LICENCIANDA E/PIBID). "[...] sempre estudar novas práticas de ensino, novos recursos de modo a atender uma sala heterogênea [...]” (LICENCIANDO B/ PIBID).
}

Nos relatos citados, é evidente a preocupação em continuar a formação, o aprofundamento em práticas educativas e também o comprometimento, apesar das dificuldades em buscar um ensino de qualidade transformando realidades. Essa visão pode ter sido provocada pela própria vivência no PIBID, já que o discurso é comum para todos os participantes e entrevistados. Esse é um processo que permanece em constante desenvolvimento, o desejo de continuar pesquisando e estudando diferentes estratégias de ensino evidenciam uma inclinação para a busca por mudanças, por melhorias, por um trabalho com uma qualidade que seja percebida no exercício da profissão (DAMASCENO; SANTOS 2019).

De acordo com Galindo (2004), a partir das experiências vividas ao longo da vida, o sujeito passa por transformações como efeito da ação social, das reações dentro de uma sociedade. O processo de identificação se inicia a partir da atração por parte do indivíduo que cria um vínculo com determinado objeto, assim, a busca para a satisfação do seu desejo se inicia 
na escolha do caminho para se chegar até ele. Para os que escolheram a docência desde cedo, o primeiro passo para conseguir se tornar um profissional é o ingresso em uma licenciatura.

Defendemos, como já proposto em estudos anteriores, que é no agir cotidiano que novas possibilidades de interações podem ser estabelecidas, bem como, confirmar a constituição do desenvolvimento humano em sua complexidade, espaço esse que materializa o processo de ensinar a pensar - o que exige a construção e reconstrução do professor crítico e reflexivo de sua prática profissional (GOMES; SOUZA, 2011; 2012). No entanto, tais ações dependem de ações mediadoras, que possibilitem a configuração de sentido que ampliem a vivência no programa, como um espaço profícuo de "certificação e segurança na escolha profissional, condição nuclear para a configuração da identidade e autonomia docente" (GOMES; SOUZA, 2014).

\section{CONSIDERAÇões FINAIS}

Tendo por base os objetivos do estudo, não propomos quaisquer generalizações, apenas buscamos entender as concepções dos informantes da pesquisa, bem como, suas experiências em prol da análise de como os espaços de formação inicial ofertado pelo Programa Institucional de Bolsas de Iniciação à Docência - PIBID e suas potencialidades atuam na configuração da identidade profissional docente.

Podemos evidenciar, a partir dos indicadores obtidos nos relatos dos participantes vinculados ao PIBID, que a vinculação ao programa é avaliada como uma ação que potencializa a consolidação da identidade profissional docente, pois, efetivamente, favorece a vivência da realidade institucional da futura profissão. No entanto, pudemos confirmar que, mesmo que o programa favoreça um novo e importante lócus formativo, nem sempre as ações e vivências potencializam a configuração plena de elementos nucleares para a identidade docente.

Entre os relatos e análises, pode ser constatado que muitas compreensões deflagradas pelos licenciandos permanecem ainda alinhadas a um reconhecimento e representação da carreira docente, muito mais como uma forma de reforçar e reproduzir dos discursos e explicações da realidade escolar, do que como potencializadoras de entendimentos e ações de transformações.

No entanto, defendemos que o desafio do programa é romper com as representações da profissão que, como percebido nas diferentes falas, pouco contribui para a qualificação da formação e ação docente. Nessa perspectiva, favorecer um espaço formativo de enfrentamento e autonomia aos licenciandos como condição para o domínio de conhecimentos e desenvolvimento de habilidades inerentes às ações educacionais, oferecer práticas educativas que possibilitem a incorporação do princípio da reflexão e transformação das realidades escolares, e fortalecer o entendimento de que a qualificação da formação e atuação está atrelada à configuração da profissão como uma ação histórica, social e relacional.

Concluímos com base nas informações construídas na pesquisa, assim como por meio das proposições conceituais abordadas, que a Psicologia Histórico Cultural, ao compreender o desenvolvimento do sujeito constituído nas interações que estabelece com o meio físico e social, por intermédio da apropriação da cultura, que se efetiva pela mediação da 
linguagem, favorece sobremaneira as análises e proposições no campo formativo de professores, com enfoque as discussões sobre identidade profissional, sobretudo ao valorizar o lugar das emoções na culminância do processo de humanização do indivíduo, ou seja, dos sujeitos professores.

\section{REFERÊNCIAS}

ABRAHÃO, M. H. M. B. Profissionalização docente e identidade - a invenção de si. Educação, Porto Alegre; n. esp., p. 163-185, out. 2007.

AGUIAR, W. M. J., OZELLA, S. Apreensão dos sentidos: aprimorando a proposta dos núcleos de significação. R. Bras. Est. Pedag., Brasília, v. 94, n. 236, 299-322, 2013.

ANADON, S. "Big Teacher" Brasil: a identidade de professoras de séries iniciais do $1^{\circ}$. grau. Dissertação de Mestrado. Pelotas: Faculdade de Educação/UFPel, 2003.

BOLÍVAR, A. La identidad profesional del profesorado de secudaria: crisis y reconstrucción. Aljibe, Málaga, 2006.

BRASIL. Decreto no. 7.219, de 24 de junho de 2010. Dispõe sobre o Programa Institucional de Bolsa de Iniciação à Docência - PIBID e dá outras providências. Diário Oficial da União. Brasília: Casa Civil da Presidência da República, jun. 2010.

CAPES. Pibid - Programa Institucional de Bolsa de Iniciação à Docência, 2018. Disponibilidade em: Acesso em: 8 abr. 2019.

DEROUET, J. L. La profession d'enseignant comme montage composite. Éducation Permanente, n. 96, p. 61-71, 1988.

FONSECA, S. Ser professor no Brasil: história oral de vida. Campinas: Papirus, 1997. GALINDO, W. C. M. A construção da Identidade Docente Profissional Docente. Psicologia, Ciência e Profissão, p. 14-23, 2004.

GATTI, B. A. Formação de professores: condições e problemas atuais. Fundação Carlos Chagas. Revista Brasileira De Formação De Professores - RBFP, v. 1, n. 1, p. 90-102, mai. 2009.

GATTI, B. A. Formação de Professores no Brasil: Características e problemas. Educação e Sociedade. Campinas, v. 31, n. 113, p. 1.355-1.379, out./dez. 2010.

GATTI, B. A.; BARRETTO, E. S. S. e ANDRÉ, M. E. D. A. Políticas docentes no Brasil - um estado da arte. Brasília, set. 2011. 
GOMES, C.; BAZON, F. V. M.; SOUZA, V. L. T. Significados e sentidos da Educação Inclusiva: mobilizando afetos e inovando ações formativas docentes. In: Enrico Bocciolesi, Sílvia Ester Orrú (Orgs.). Educar para transformar o mundo: inovação e diferença por uma educação de todos e para todos: Educar para transformar el mundo: innovación y diferencia por una educación de todos y para todos. Campinas: Librum Editora, Ebook, 2018.

GOMES, C.; DUGNANI; L. A. C.; RAMOS, V. R. L. Contribuições da Psicologia Escolar à formação inicial e continuada de profissionais da saúde e educação. In: Vera Lúcia Trevisan de Souza et al. Psicologia Escolar Crítica: atuações emancipatórias nas Escolas Públicas. Campinas: Editora Alínea, 2018.

GOMES, C.; FELICIO, H. M. S.; ALLAIN, L.; OLIMPIO, F. M. P.; CARVALHO, A. J. S. PIBID: Potencialidades e Limites entre a formação e atuação profissional docente. Pesquiseduca, v. 6, p. 323-338, 2014.

GOMES, C.; FELICIO, H. M. S.; ALLAIN, L. R. O PIBID na ótica dos licenciandos: possibilidades e limites no desenvolvimento do programa. Revista Educação. Santa Maria | v. 39 | n. 2 | p. 339-352 | mai./ago. 2014.

GOMES, C.; FELICIO, H. M. S.; BATISTA, P. O. O PIBID e a profissionalização dos supervisores de área. Comunicações (UNIMEP), v. 23, p. 109, 2016.

GOMES, C.; SOUZA, V. L. T. Educação, Psicologia Escolar e Inclusão: aproximações necessárias. Psicopedagogia (São Paulo), v. 28, p. 41-50, 2011.

GOMES, C.; SOUZA, V. L. T. Fracassos, representações e exclusões: discussões preliminares na escola. Psicopedagogia (São Paulo), v. 26, p. 41-47, 2009.

GOMES, C. SOUZA, V. L. T. O PIBID como mediador da configuração de sentidos sobre a docência: as contribuições da psicologia para a formação de professores. Relatório de Estágio de Pós-doutoramento. Campinas: Pontifícia Universidade Católica de Campinas, 2014.

GOMES, C.; SOUZA, V. L. T. Psicologia e inclusão escolar: reflexões sobre o processo de subjetivação de professores. Psicologia: Ciência e Profissão (Impresso), v. 32, p. 1, 2012. GONZALEZ REY, F. Pesquisa Qualitativa em Psicologia - caminhos e desafios. São Paulo: Thomson, 2002.

HYPOLITO, A. M.; VIEIRA, J. S.; GARCIA, M. M. A.; FERREIRA, M. O. V. Trabalho Docente, Profissionalização e Identidade: contribuições para a construção de um campo de estudo, 2003.

JESUS, S. N. Desmotivação e crise de identidade na profissão docente. KATÁLYSIS, n. 2, p. 192-202, Florianópolis, 2004. 
JUNGES, K. S. Trajetórias de vida, constituição profissional e autonomia de professores. Face, União da Vitória, 2006.

LIBÂNEO, J. C. O dualismo perverso da escola pública brasileira: escola do conhecimento para os ricos, escola do acolhimento social para os pobres. Educação e Pesquisa, São Paulo, v. 38, n. 1, p. 13-28, 2012.

LIMA, L. M.; SILVA, D. M. S.; CAIXETA, J. E. O PIBID e a identidade docente: a visão dos/as licenciandos/as sobre as contribuições do programa na Universidade de Brasília. Ciências em Foco, v. 11, n. 2, 27, dez. 2018.

MARCELO, C. A identidade docente: constantes e desafios. Revista Brasileira de Pesquisa sobre Formação Docente, v. 1, n. 1, p. 109-131, Belo Horizonte.

MARCELO, C. Desenvolvimento profissional docente: passado e futuro. Revista Ciência da Educação, n. 8, abr. 2009

MARTINS, L. M. O desenvolvimento do psiquismo e a educação escolar: Contribuições à luz da psicologia histórico-cultural e da pedagogia histórico crítica. São Paulo: Universidade Estadual Paulista Júlio de Mesquita Filho (UNESP), 2012.

MAZZOTTI, A. J. A. Representações da identidade docente: uma contribuição para a formulação de políticas. Rio de Janeiro, dez. 2007.

NÓVOA, A. Formação de professores e profissão docente. Os professores e sua formação. Lisboa: Dom Quixote, 1992.

NÓVOA, A. Pensar alunos, professores, escolas, políticas. Educação Cultura e Sociedade, v. 2, n. 2, p. 7-17, dez. 2012.

OBARA, Cássia Emi; BROIETTI, Fabiele Cristiane Dias; PASSOS, Marinez Meneghello. Contribuições do PIBID para a construção da identidade docente do professor de Química. Ciênc. educ. (Bauru), Bauru, v. 23, n. 4, p. 979-994, dez. 2017.

OLIARI, F. A. S.; TENROLLER, R. M.; ROQUETTE, R. F.; NEZ, E. De. Refletindo sobre a identidade e a formação do professor da educação superior, 2012.

RANKEL, L. F. A (des)construção da identidade docente. Profissão Docente, 2009.

SANTOS, B. S. dos; ANTUNES, D. D.; BERNARDI, J. O docente e sua subjetividade nos processos motivacionais. Educação, Porto Alegre, v. 31, n. 1, p. 46-53, abr. 2008. 
SANTOS, J. C.; COSTA, H. L.; DAMASCENO, E. J. S. A Constituição da identidade docente a partir do PIBID: uma experiência de formação de licenciandos em computação no IFBA-Campus Santo Amaro - BA. Revista Humanidades e Inovação, v. 6, n. 10, 2019.

SAVIANI, D. Educação brasileira: estrutura e sistema, 2. ed. São Paulo: Saraiva, 146 p. 1975.

SILVA JÚNIOR, C. A. Fortalecimento das políticas de valorização docente: proposição de novos formatos para cursos de licenciatura para o estado da Bahia. CAPES, UNESCO, Brasília, 2010.

TARDIF, M.; LESSARD, C. O trabalho docente: elementos para uma teoria da docência como profissão de interações humanas. Petrópolis: Vozes, 2005.

VENZKE, L. H. D. Professoras da educação infantil em Pelotas: identidades em construção. Dissertação de Mestrado. Faculdade de Educação/UFPel, Pelotas, 2003.

VIGOTSKI, L. S. Imaginación y creatividad del adolescente. In: VIGOTSKI, Lev S. Psicologia Infantil - Obras Escogidas, v. IV (edição dirigida por Alvarez, A. e Del Rio, P.). Madri: Visor, p. 205-223 (original de 1931), 1996.

VIGOTSKI, L. S. Problemas del desarrollo de la psique - Obras Escogidas, v. III (edição dirigida por Alvarez, A. e Del Rio, P.). Madri: Visor, p. 11-340 (original de 1931), 1995.

VIGOTSKI, L. S. Psicologia da arte. São Paulo: Martins Fontes (originalmente, publicado em 1925), 2005.

\section{Dados Das AUTORAS:}

\section{Caroline Mariae Pereira}

Mestre em Educação e Licenciada em Química pela Universidade Federal de Alfenas/MGBrasil.claudia.gomes@unifal-mg.edu.br

\section{Tassiana Garcia Lopes}

Licenciada em Química pela Universidade Federal de Alfenas/MG- Brasil. claudia.gomes@unifal-mg.edu.br

\section{Claudia Gomes}

Professora do Instituto de Ciências Humanas e Letras da Universidade Federal de Alfenas/ MG- Brasil.cg.unifal@gmail.com

Submetido em: 2-7-2019

Aceito em: 14-7-2020 